\title{
Sağlıklı Bireylerden ve Candida - İlişkili Protez Stomatitili Hastalardan İzole Edilmiş Stok C.albicans Suşları Arasındaki C.dubliniensis Prevalansının Moleküler Yöntemlerle Retrospektif Olarak Araştırılması
}

\author{
Retrospective investigation of C.dubliniensis prevalence among stock C.albicans strains isolated \\ from healthy individuals and patients with Candida-associated prosthetic stomatitis by molecular \\ methods
}

Derya KAZANCI ${ }^{1}$, Tanju KADİR ${ }^{2}$, Korkut $\operatorname{ULUCAN}^{1} \oplus$

Öz

Amaç: Candida-ilişkili protez stomatiti (C-İPS), protez takan hastaların yaklaşık \%50-65'inde saptanan oral kandidiyazın en sık görülen şeklidir. Candida albicans'ın enflamatuar patolojiden sorumlu başlıca tür olduğu gösterilmiştir. İlk kez 1995 yılında Dublin'de tanımlanan Candida dubliniensis'in fenotipik özellikler ve neden olduğu lezyon türü açısıdan C. albicans'a çok benzediği saptanmıştır. Geçmiş yıllarda C.albicans olarak tanımlanan suşların C.dubliniensis olma olasılı̆̆ı nedeniyle C.dubliniensis' in tarihsel prevalansını belirlemeye gerek duyulmuştur.

Gereç ve Yöntemler: Bu çalışmada, oral örneklerden izole edilip sadece fotipik yöntemlerle C.albicans olarak tanımlanan ve 2003 yılına kadar stok koleksiyonunda tutulan 81 maya suşu moleküler yöntemlerle yeniden incelenmiştir.

Bulgular: Polimeraz zincir reaksiyonu ve restriksiyon endonükleaz reaksiyonları ile yapılan genotipik incelemede sağlıklı bireylerden izole edilen 45 C.albicans suşun 4'ü $(\% 8,8)$ C.dubliniensis, ancak CİPS'li hastalardan izole edilen 36 suşun tamamının C.albicans olduğu tespit edilmiştir.

Sonuç: Bu retrospektif araştırmanın sonucunda ağızdan izole edilmiş 81 maya suşu arasında C.dubliniensis prevelansının \% 4.9 olduğu, ancak C-İPS patogenezinde etkin olmadığ 1 anlaşı1mıştır.

Derya Kazanc1 (瓜)

Marmara University, Faculty of Dentistry, Medical Biology and Genetics, Basibuyuk Yolu 9/3 Maltepe/ Istanbul, Turkey, 34854.

e-mail:deryakazanci@marmara.edu.tr

Tanju Kadir

Marmara University, Faculty of Dentistry, Department of Microbiology, Istanbul, Turkey.

Korkut Ulucan

Marmara University, Faculty of Dentistry, Medical Biology and Genetics, Istanbul, Turkey.

Submitted / Gönderilme: 01.05 .2021

Accepted/Kabul: 05.07.2021
Anahtar Kelimeler:C.dubliniensis, C.albicans, Candidailişkili protez stomatiti

Abstract

Objectives:Candida-related denture stomatitis (C-RDS), is the most frequent form of oral candidiasis, being detected in approximately $50 \%-65 \%$ of denture-wearing patients. Candida albicans has been shown to be the principal species responsible for inflammatory pathology. Candida dubliniensis, first described in Dublin in 1995, was found to be very similar to C. albicans in terms of phenotypic features and the type of lesion it causes. It was necessary to determine the historical prevalence of C.dubliniensis due to the possibility that the strains identified as C.albicans in the past years were C.dubliniensis.

Materials and Methods: In this study, 81 yeast strains isolated from oral samples and identified as C.albicans only by photypic methods and kept in the stock collection until 2003 were re-examined by molecular methods.

Results:In the genotypic examination performed by polymerase chain reaction and restriction endonuclease reactions, 4 (8.8\%) of 45 C.albicans strains isolated from healthy individuals were found to be C.dubliniensis, but all 36 strains isolated from patients with C-RDS were C.albicans.

Conclusions: As a result of this retrospective study, it was found that the prevalence of C.dubliniensis among 81 yeast strains isolated orally was $4.9 \%$, but it was not effective in the pathogenesis of C-RDS.

Keywords:C.dubliniensis, C.albicans, Candida related denture stomatitis

\section{Giriş}

Candida, insanların büyük bir kısmının ağız mikrobiyotasında normalde az sayıda bulunan kommensal mayadır (Raju \& Rajappa, 2011; Deo \& Deshmukh. 
2019). Sağlıklı konaklarda zararlı olarak kabul edilmez, ancak kandidiyaz ile sonuçlanan firsatçı enfeksiyonlara neden olabilir (Akpan \& Morgan, 2002; Vila ve ark., 2019). Yaşlılık, ağız ortamında ve dolayısıyla ağız mikrobiyotasında değişikliklere neden olan protez takmayı gerektirir (Zomorodian ve ark, 2011). Ağız ortamındaki mikroplar, protez özelliklerine, Candida türlerine ve ağız hijyeni uygulamalarına bağlı olarak protez yüzeyini kolonize eder ve yapışkan biyofilm oluşturur (Salerno ve ark., 2011; Prakash ve ark., 2015; Mousa ve ark., 2020). Polimetil metakrilat gibi sentetik polimerlerden yapilan protezler doğal olarak mikro gözeneklidir ve bu nedenle Candida'nın kolayca tutunmasına ve kolonileşmesine neden olur. Günümüzde, kolonileşmeyi azaltmaya yönelik çalışmalar hala sürmektedir (Mendez-Serrano ve ark., 2020 ; Acosta ve ark., 2020).Ayrıca diyet, bağışıklık yetersizliliğ̣i, yüzey pürüzlülüğü, protez temizleyicileri, temizleme yöntemleri, besin kalıntılı tükürük, yaş, hormonal dengesizlik ve diğer predispozan faktörler gibi birçok konak faktörü protez yüzeyine tutunmayı ve kolonizasyonu kolaylaştırır(Odds ve ark., 1998Akpan \& Morgan, 2002; Rodrigues ve ark., 2019; Thiyahuddin ve ark., 2019). Protezler yüzeyinde gelişen mikrobiyal biyofilm, Candida ilişkili protez stomatiti (C-İPS) olarak bilinen kandidiyaz patogenezi başlatabilir (Salerno ve ark, 2011; Badaró ve ark., 2020).Şimdiye kadar yapılan çalışmalarda, Candida albicans'ın C-İPS ile ilişkili başlıca tür olduğu gösterilmiştir (Akpan \& Morgan, 2002; Arias ve ark., 2008; Gendreau \& Loewy, 2011;Gad \& Fouda, 2020). Fakat artan ilaç kullanımı, edinsel immün yetmezlik sendromu (AIDS) ve diğer etkenlere bağlı olarak albicans olmayan Candida türlerinin de patojen olabileceği bildirilmiştir (Maenza ve ark., 1998; Kurnatowska AJ, 2001; Akpan \& Morgan, 2002, Muadcheingka \&Tantivitayakul, 2015). Özellikle AIDS'li hastaların ağız boşluğundan izole edilenler arasında Candida dubliniensis dikkat çekmiştir (Odds ve ark., 1998; Aboualigalehdari ve ark., 2020). $\mathrm{Bu}$ türün önemli bir özelliği, mikozların tedavisinde yaygın olarak kullanılan bir antifungal olan flukonazole in vitro direnç geliştirmesidir (Moran ve ark., 1998; Aboualigalehdari ve ark., 2020). C.dubliniensis ilk defa 1995 yılında Dublin'de Sullivian ve ark. (Sullivan ve ark .,1995; Coleman ve ark., 1997 ) tarafindan fenotipik (üreme ve görünüm) özellikleri açısından C.albicans'a çok benzeyen fakat genetik düzeyde ondan farklı olan yeni bir tür olarak tanımlanmıştır. Son 15 yılda yapılan çalışmalar, bu türün HIV ile enfekte hastalarda, diyabet hastalarında ve ayrıca sağlıklı kişilerde hastalıkla ilişkili olduğunu ortaya koymuştur (Rodrigues ve ark., 2019; Thiyahuddin ve ark.,
2019; Aboualigalehdari ve ark., 2020). Epidemiyolojik çalışmalar, HIV ile enfekte hastaların ağız boşluğunda $C$. dubliniensis prevalansının \%1.5 ile 32 arasında değiştiğini göstermiştir (Sullivan ve ark., 1995; Coleman ark., 1997; Clark-Ordo' nez ve ark., 2017). C. dubliniensis'in $C$. albicans ile birçok fenotipik özelliği paylaşması nedeniyle, geçmiş yıllarda C. albicans olarak tanımlanan bazı oral klinik izolatların, C. dubliniensis' in yanlış tanımlanmış izolatları olabileceği düşünülmüştür (Odds ve ark., 1998 ; Sant'ana Maiano ve ark., 2003). Bu nedenle çalışmamızda 19972003 yılları arasında Marmara Üniversitesi Diş Hekimliği Fakültesi Mikrobiyoloji laboratuvarına gönderilen 45 sağlıklı ve 36 C-İPS'li bireyin ağız örneklerinden üretilmiş, sadece fenotipik yöntemlerle C.albicans olarak tanımlanmış toplam 81 stok suş arasında C.dubliniensis varlığı moleküler yöntemler kullanılarak araştırılmıştır.

\section{Gereç ve Yöntemler}

Bu çalışmamızda, 1997-2003 yılları arasında Marmara Üniversitesi Diş Hekimliği Fakültesi Mikrobiyoloji Bilim Dalı laboratuvarına gönderilen dil üstü ve damak sürüntü örneklerinden izole edilmiş sadece fenotipik yöntemlerle tanımı yapılmış 81 stok C.albicans suş araştırılmıştır. $\mathrm{Bu}$ suşların 36's1 C-İPS bulgusu gösteren 40 - 70 yaş aras1 protez kullanan hastalardan; 45'i ise 0-60 yaş arası, protez kullanmayan (sağlıklı) bireylerden elde edilmiştir. Çalışmamızda kontrol suşu olarak C.albicans CBS 6431 ve C.dubliniensis CBS 7987 kullanılmıştır.

Deney başlangıcında, stok suşlar CHROMagar Candida besiyeri plaklarına ekilmiş ve $37^{\circ} \mathrm{C}$ de 48 saat inkübe edilmiştir. C.dubliniensis' tanımlamak için önce germ tüp, klamidospor oluşturma ve farkl1 1sı derecelerinde $\left(37^{\circ} \mathrm{C}\right.$, $42^{\circ} \mathrm{C}$ ve $48^{\circ} \mathrm{C}$ ) üreme gibi fenotipik ayırıcı tanı yöntemleri uygulanmış, daha sonra moleküler tanı yöntemleriyle karşılaştırılmıştır.

Suşlara uygulanan moleküler yöntemler sırası ile DNA izolasyonu, PCR tekniği ile HWP1 geni amplifikasyonu ve RFLP tekniği ile amplikonların kesilmesi şeklinde olmuştur. DNA izolasyonu "High Pure PCR Template Preparation" ticari kiti kullanılarak gerçekleştirilmiştir. Ardından PCR tekniği ile suşların HPW1 (Hyphal Wall Protein 1) gen uzunluğu polimorfizmleri görüntülenmiştir. Son olarak da RFLP tekniği ile oluşan gen amplikonlarının BamH1 restriksiyon enzimi ile reaksiyonu sonucu oluşan parça gen polimorfizmleri görüntülenerek incelenmiştir (Romeo ve ark,. 2006) . 


\section{Bulgular}

C-IPS'li hastalardan izole edilen ve sadece klasik fenotipik yöntemlerle C.albicans olarak tanımlanan 36 suş, hem fenotipik hem de PCR yöntemleriyle yeniden değerlendirilmiş, tamamının C.albicans olduğu doğrulanmıştır. Ancak protez kullanmayan sağliklı bireylerden izole edilen 45 C.albicans suşunun 4'nün C.dubliniensis olduğu tespit edilmiştir. Bu suşların 4'ü de 8 yaş altı sağlıklı çocuklarda görülmüştür (Tablo 1).

Tablo 1: 81 adet stok şusun moleküler yötemler kullanılarak ortaya çıkarılmış reidentifikasyon oranları

\begin{tabular}{|l|l|c|}
\hline $\begin{array}{c}\text { Fenotipik yöntemle } \\
\text { tanımlanmış (1997- } \\
\text { 2003) }\end{array}$ & $\begin{array}{c}\text { Genotipik yöntemle } \\
\text { geriye dönük } \\
\text { reidentifikasyon } \\
\text { sonuçları }\end{array}$ & $\begin{array}{c}\text { Reidentifikasyon } \\
\text { oranı }\end{array}$ \\
\hline $\begin{array}{l}45 \text { adet stok } \text { C. albicans } \\
\text { suşu } \\
\text { (sağlıklı birey kökenli) }\end{array}$ & $\begin{array}{l}41 \text { adet } \text { C.albicans } \\
4 \text { adet } \text { C.dubliniensis }\end{array}$ & $\% 8.8$ \\
\hline $\begin{array}{l}36 \text { adet stok } \text { C.albicans } \\
\text { suşu } \\
\text { (protez stomatitli } \\
\text { kökenli) }\end{array}$ & 36 adet C.albicans & $\% 0$ \\
\hline $\begin{array}{l}\text { Total } 81 \text { stok adet } \\
\text { C.albicans suşu }\end{array}$ & $\begin{array}{l}77 \text { adet } \text { C.albicans } \\
4 \text { adet } \text { C.dubliniensis }\end{array}$ & $\% 4.9$ \\
\hline
\end{tabular}

\section{Tartışma}

Ağız boşluğundaki 700 kadar mikroorganizma türü arasında Candida cinsinden maya mantarları da bulunur (Prakash ve ark., 2015; Deo \& Deshmukh, 2019). Genel popülasyonda, herhangi bir semptom yapmaksızın taşıma oranlarının \%20 ile \%75 arasında değiştiği bildirilmiştir (Akpan \& Morgan, 2002; Samaranayake, 2009; Mun ve ark., 2015;Kimsa ve ark., 2020). Şeker hastaları ve bağışıklık sistemi baskılanmış bireylerde bu oranın daha da yüksek olduğu gözlenmiştir (Lourenço ve ark., 2017,Sampath ve ark., 2019). C. albicans, insan ağız boşluğundan izole edilen en yaygın (\%20-50) tür olmasının yanı sira (Noble ve ark., 2017; Khan İ, 2020), C. glabrata, C. tropicalis ve C. dubliniensis gibi diğer türler de daha az sıklıkla bulunmaktadır. (Martin ve ark., 2010 ; Kimsa ve ark., 2020). Ağız boşluğunda kommensal olarak az sayıda yaşayan bu organizmaların, bazı lokal ve sitemik faktörlerin etkisiyle aşırı üremelerinin bir sonucu olarak kandidiyaz gibi firsatçı enfeksiyonlara neden oldukları tespit edilmiştir (Singh ve ark., 2014; Millsop \& Faze, 2016; Hellstein \& Marekg , 2019; Vila ve ark, 2020 ).Oral kandidiyaz, özellikle erken ve sonraki yaşamda en sık görülen insan mantar enfeksiyonudur (Akpan \& Morgan, 2002; Sharma
A, 2019). Yaşlılarda, özellikle protez takanlarda ve aynı zamanda diabetes mellitus gibi sistemik bir hastalı̆̆ 1 veya bağışıklık yetmezliği olan kişiler arasında yaygın bir sorun olduğu görülmüştür (Odds ve ark., 1998; Akpan \& Morgan, 2002; Rodrigues ve ark., 2019; Thiyahuddin ve ark., 2019; Sharma, 2019).

Bir protezin ağız boşluğuna yerleştirilmesi, düşük oksijenli, düşük $\mathrm{pH}$ 'lı ve anaerobik bir ortamla kandida üremesine elverişli bir mikro ortam oluşturur (Gleiznys ve ark., 2015; Vila ve ark, 2020.) Bunun nedeni, Candida türlerinin akriliğe daha iyi yapışması, protez yüzeyleri altında tükürük akışının azalması, uygun olmayan protez veya kötü ağız hijyeni olabilir (Akpan \& Morgan, 2002; Baran \& Nalçaci, 2009; Prakash ve ark., 2015).

Protez kullanımına bağlı olarak gelişen kandidiyaz, kronik atrofik kandidiyaz veya Candida ilişkili protez stomatiti olarak tanımlanmıştır (Sharma, 2019 ; Vila ve ark, 2020). Epidemiyolojik çalışmalar, bu hastalı̆̆ 1 geliştiren bireylerin tükürük, damak mukozası ve dil mukozası örneklerinden izole edilen $C$ albicans'ın protez stomatiti gelişiminin ana nedeni olduğunu, ancak hastalığın patogenezinde rol oynayabilecek diğer Candida türlerinin varlığını da bildirmiş̧ir (Gasparoto ve ark., 2009; Zomorodian ve ark, 2011: Prakash ve ark., 2015). Özellikle, Temmuz 1995'de Dublin'de tanımlanan C.dubliniensis' in ilk izolasyonu HIV'li hastalarda tekrarlayan ağız kandidiyaz lezyonlarından yapılmıştır (Sullivan ve ark., 1995; Coleman ve ark., 1997 ).

C.dubliniensis'in C.albicans ile birçok fenotipik özelliği paylaştığı ve neden olduğu kandidiyaz hastalığının klinik bulgularının sıklıkla eritematöz şeklinde olduğu gözlenmiştir (Coronado ve ark., 2013; Liverio ve ark., 2017). C-İPS'in klinik bulgularının aynı şekilde olduğu ve lezyonlardan izole edilen mayaların \%70 - \%80 kadarını C.albicans kökenleri oluşturduğu tespit edilmiştir (Akpan \& Morgan, 2002; Arias ve ark., 2008; Gendreau \& Loewy, 2011; Gad \& Fouda, 2020). Bu durum aklımıza geçmişte yapılan çalışmalarda C.albicans olarak tanımlanmış izolatların kaçının C.dubliniensis olabileceği sorusunu getirmiştir. $\mathrm{Bu}$ nedenle çalışmamızın amacı, geçmişte sağlıklı bireyler ve C-İPS'li hastalardan izole ettiğimiz C.albicans suşlarını yeniden değerlendirip, ne kadarının C.dubliniensis olduğunu araştırmak olmuştur.

C.dubliniensis'in ilk tanımlanmasından sonra yapılan çalışmalarda oral kandidiyaz belirtileri bulunan semptomatik HIV pozitif hastalarını \%32'inde ve asemptomatik HIV pozitif bireylerin $\% 25$ 'inde C.dubliniensis kökeni tespit 
edilmiştir(Coleman ve ark., 1997).Bu çalışmaları retrospektif çalışmalar takip etmiş ve kültür koleksiyonlarında yanlış tanımlanmış suşlar olduğu bildirilmiş̧tir (Odds ve ark., 1998). Bilinen en eski C.dubliniensis stok suşu 1957'de İngiltere'de ölmüş bir hastanın akciğer örneğinden izole edilmiştir. Daha sonraki çalışmalarda C.dubliniensis kökeni, sağlıklı bireylerin (Mosca ve ark., 2005), diyabet ve kistik fibrözlü hastaların ağzından izole edilmiştir (Pinjonve ark., 1998;Willis ve ark., 2000; Peltroche ve ark., 2002). Türkiye'de ise ilk izolasyon 1998-99 yıllarında gerçekleşmiştir (Yücel A \& Kantarcıŏglu, 1996; Hilmioğlu ve ark., 1998).

C. albicans'1 C. dubliniensis'ten ayırabilen moleküler yöntemleri kullanan çalışmalar, C-İPS'li klinik örneklerde C. dubliniensis izolatı olmadığını veya sadece bir iki izolatın var olabileceğini bildirmiştir. Mosca ve arkadaşlarının yaptığı bir çalışmada 12 ergenin protez ile temas eden üst damak bölgesinden alınan sürüntü örneklerinden sadece birinden C.dubliniensis suşu izole edilmiştir (Mosca ve ark., 2005). Yapılan bir başka çalışmada orta ve ileri yaş grubu 45 protez stomatitli hastanın kullandığı protez materyali ve mukozalarından alınan örneklerden sadece birinde C.dubliniensis suşu bulunmuştur (Marcos-Arias ve ark., 2009). Pintovearkadaşlarınınyaptığı birçalışmada 70 sağlıklı ve 70 protez stomatitli hastadan alınan üst damak sürüntü örneklerinden C.dubliniensis suşu izole edilememiştir (Pinto ve ark., 2008). Bizim çalışmamızda 1997-2003 yıllarında protez stomatitli 40-60 yaş arası hastalardan izole edilmiş ve stok C.albicans olarak tanımlanmış stok 36 suş arasında yapılan araştırmanın sonucunda C.dubliniensis suşu saptanmamıştır. Bununla birlikte 0-60 yaş arası sağlıklı bireylerden izole edilerek C.albicans olarak tanımlanmış 45 stok suşdan 4'ü C.dubliniensis olarak tanımlanmıştır. İlginç olan; yeniden adlandırılan bu 4 suşun 3-8 yaş arası çocuklardan izole edilmiş olmasıdır. Elde ettiğimiz verilerin önceki raporlara benzer şekilde olduğu görülmüştür.

Bazı çalışmalar protez kullananlarda protez kaynaklı stomatit varlığına bakılmaksızın C.dubliniensis prevelansını araştırmış ve yaklaşık \%10 oranında olduğunu bildirmiştir (Gasparoto ve ark., 2009; Zomorodian ve ark,2011). Ancak protez altındaki mukozadan izole edilen C.dubliniensis suşlarının kaçının lezyonlu veya lezyonsuz bölgeden olduğu hakkında bilgi verilmemiştir.

Literatür bilgileri ve elde ettiğimiz veriler 1şığında Candida ilişkili protez stomatiti'li hastalarda C.albicans 'ın patojenik bir maya olarak hala etkinliğini koruduğu; C.dubliniensis prevalansının ise ya düşük olduğu ya da hiç olmadığı (Marcos -Arias ve ark.,2009; Gauch ve ark., 2018; Senna ve ark., 2018; Aslani ve ark., 2018) ve bu konunun aydınlatılması için daha farklı epidemiyolojik çalışmalara ihtiyaç duyulduğu anlaşılmıştır.

\section{Teşekkür}

$\mathrm{Bu}$ çalışma Marmara Üniversitesi Bilimsel Araştırma Projeleri Komisyonu tarafindan SAG-CYLP-030.408.0057 No'lu proje ile desteklenmiştir.

\section{Kaynaklar}

1. Aboualigalehdari E, Birgani MT, Fatahinia M, Hosseinzadeh M. Oral colonization by Candida species and associated factors in HIV-infected patients in Ahvaz, southwest Iran. Epidemiol Health. 2020; 42: e2020033.

2. Acosta LD, Perez-Camacho O, Perez-Camacho O, Acosta R, Escobar DM, Gallardo CA, Sanchez-Vargas LO. Reduction of Candida albicans biofilm formation by coating polymethyl methacrylate denture bases with a photopolymerized film J ProsthetDent. 2020; 124(5): 605-613.

3. Akpan A, Morgan R. Oral Candidiasis. Postgrad Med J. 2002; 78: 455-459.

4. Arias CM, Vicenta JL, Sahand IH, Eguia A, De-Juan A, Madariaga L, Aguirre JM, Eraso E, Qindos G. Isolation of Candida dubliniensis in denture stomatitis. Arch Oral Biol.2008; 54: 127-131.

5. Aslani N, Janbabaei G, Abastabar M, Meisi JF, Babaeian M, Khodavaisy S, Boekhout T, Badali H. Identification of uncommon oral yeasts from cancer patients by MALDI-TOF mass spectrometry. BMC Infect Dis.2018; 18(24).18(1):24.

6. Badaro MM, Bueno FL, Arnez RM, Oliveira VC, Macedo APM, Souza RF, Paranhos HFO, Silva-Lovato $\mathrm{CH}$. The effects of three disinfection protocols on Candida spp., denture stomatitis, and biofilm: A parallel group randomized controlled trial.J Prosthet Dent 2020; 124(1): 690-698.

7. Baran I, Nalçaci R. Self-reported denture hygiene habits and oral tissue conditions of complete denture wearers. Arch. Gerontol. Geriatr. 2009; 49: 237-241.

8. Clark-Ordo' nez I, Callejas-Negrete OA, Arechiga-Carvajal ET, Mourino-P erez ' RR. Candida species diversity and antifungal susceptibility patterns in oral samples of HIV/AIDS patients in Baja California, Mexico Med Mycol.2017;55: 285-294.

9. Coleman DC, Sullivan DJ, Bennett DE, Moran GP, Barry HJ, Shanley DB. Candidiasis: the emergence of a novel species, Candida dubliniensis. AIDS. 1997 11(5): 557-567.

10. Coronado-Castello, Jimenez-Soriano Y. Clinical and microbiological dianosis of candidiasis. J Clin Exp Dent. 2013; 5(5): 279-286.

11. Deo PN, Deshmukh R. Oral Microbiome: Unveiling the fundamentals. J Oral Maxillofac Pathol. 2019; 23(1): 122-128. 
12. Gad MM, Fouda SM. Current prespective and future of Candida albicans-associated denture stomatitis treatment. Dent Med Probl.2020; 57(1): 95-102.

13. Gasparoto TH, Dionı'sio TJ, Oliveira CE, Porto VC, Gelani V, Santos CF, Campanelli AP, Lara VS. Isolation of Candida dubliniensis from denture wearers. Journal of Medical Microbiology.2009; 58: 959-962.

14. Gauch LMR, Pedrosa SS, Silveira-Gomes F, Renata AE, Marques-de-Silva S. Isolation of Candida spp. From denture-related stomatitis in Para, Brazil. Brazilian Journal of Microbiology. 2018; 49: 148-151.

15. Gendreau L, Loewy ZG. Epidemiology and etiology of denture stomatitis. J Prosthodont. 2011; 20(4):251-260.

16. Gleiznys A, Zdanavičienè E, Juozas Žilinskas. Candida albicans importance to denture wearers. A literature review. Stomatologija, Baltic Dental and Maxillofacial Journal. 2015; 17: 54-66.

17. Hellstein JW, Marekg C. Candidiasis: Red and white manifestations in the oral cavity. Head Neck Pathol. 2019; 13: $25-32$

18. Hilmioğlu S, Aydemir Ş, İnci R. Gürel SÖ, Tümbay E. Türkiye'de ilk kez izole edilen Candida dubliniensis kökeni. İnfeksiyon Derg. 1998; 12(4): 545-8.

19. KhanI, Ahmad T, Manzoor N, Rizvi MA, Uqba Raza U, Premchandani S. Evaluating the role of local host factors in the candidal colonization of oral cavity: A review update. NJMS. 2020; 11 (2): 169-175.

20. Kimsa $£$, Tokarska-Rodak M. Occurrence of Candida spp. In healthy oral microbiota. Health Probl Civilizat. 2020;14:124-30.

21. Kurnatowska AJ. Search for correlation between symptoms and sings of changes in the oral mucosa and presence of fungi. Mycoses. 2001; 44:379-382.

22. Liverio HS, Ruiz LS, Nishikaku A, Souza AC, Paula CR, Domaneschi C. Phenotypic and genotypic detection of Candida albicans and Candida dubliniensis strains isolated from oral mucosa of AIDS pediatric patients. Rev Inst Med Trop S Paulo.2017; 59: e14.

23. Lourenço AG, Ribeiro AERA, Nakao C, Motta ACF, Antonio LGL, Machado AA, Komesu MC. Oral Candida spp carriage and periodontal diseases in HIVinfected patients in Ribeirão Preto, Brazil. Rev Inst Med Trop São Paulo. 2017; 59:e29.

24. Maenza RJ, Merz WG, Gorbach SL, Bartlett NR, Blacklow NR. Candida albicans and Related Species. In:Infectious Diseases. 1998; 2th Ed, p. 213-221.

25. Marcos-Arias C, Vicente JL, Sahand IH, Eguia A, De-Juan A, Madariaga L, Aguirre JM, Eraso E, Quindós G. Isolation of Candida dubliniensis in denture stomatitis. Arch Oral Biol. 2009; 54 (2): 127 - 131

26. Martin M, Henriques M, Ribeiro AP, Fernandes R, Gonçalves V, Seabra A, Azeredo J, Oliveira R. Oral Candida carriage of patients attending a dental clinic in Braga, Portagul. Rev Iberoam Micol. 2010; 27(3): 119-124.

27. Mendez-Serrano J, Velazquez-Enriquez U, Contreras-Bulnes R, Rosa-Gómez I, Sawada T, Yamaguchi R. Adhesion of Candida albicans AND Streptococcus mutans to silver nanoparticle-modified polymetylmetharcrylate. Interciencia. 2020; 45(1).
28. Millsop JW, Faze LN. Oral candidiasis. Clin. Dermatol. 2016; 34: 487-494.

29. Moran GP, Sanglard D, Donnelly SM, Shanley DB, Sullivan DJ, Coleman DC. Identification and expression of multidrug transporters responsible for fluconazole resistance in Candida dubliniensis. Antimicrobial Agent and Chemotherapy. 1998. 1819-1830

30. Mosca CO, Moragunes MD, Brena S, Rosa AC, Ponton J. Isolation of Candida dubliniensis in a teenager with denture stomatitis. Med Oral Pathol Oral Cir Bucal. 2005; 10: 28-35.

31. Mousa MA, Lynch E, Kielbassa AM. Denture-related stomatitis in new complete denture wearers and its association with Candida species colonization: a prospective case-series. Quintessence International (Berlin, Germany : 1985). 2020; 51(7):554-565.

32. Muadcheingka T, Tantivitayakul P. Distribution of Candida albicans and non-albicans Candida species in oral candidiasis patients: Correlation between cell surface hydrophobicity and biofilm forming activities. Science Direct Archives of Oral Biology. 2015; 60: 894-901.

33. Mun M, Yap T, Alnuaimi AD, Adams GG, McCullough MJ. Oral candidal carriage in asymptomatic patients. Aust Dent J. 2016; 61: 190-195.

34. Noble, SM, Gianetti, BA ve Witchley, JN. Candida albicans cell type switching and functional plasticity in the mammalian host. Nat Rev Microbiol.2017; 15, 96-108.

35. Odds FC, Nuffel LV, Dams G. Prevalence of Candida dubliniensis 1solates in a yeast stock collectin. Journal of Clinical Microbiology. 1998; 36(10): 2869-2873.

36. Quindós G, Carrillo-Muñoz AJ, Arévalo MP, Salgado J, Alonso-Vargas R, Rodrigo JM, Ruesga MT, Valverde A, Pemán J, Cantón E, Martín-Mazuelos E, Pontón J. Candida dubliniensis to current and new antigungal agents. Chemotherapy. 2000; 46: 395-401.

37. Peltroche H, Dohmen H, Haase G. Recovery of Candida dubliniensis from sputum of cystic fibrosis patients. Mycosis. 2002; 45: 15-18.

38. Pinjon, E., D. Sullivan, I. Salkin, D. Shanley, and D. Coleman. Simple, inexpensive, reliable method for differentiation of Candida dubliniensis from Candida albicans. J Clin Microbiol. 1998; 36: 2093-2095.

39. Pinto E, Riberio IC, Ferreira NJ, Fortes CE, Fonseca PA, Figuerial MH. Correlatiom between enzyme production, germ tube formation and susceptibility to fluconazole in Candida species isolated from patients with denture related stomatitis and control individuals. J Oral Pathol Med. 2008; 37 (10): 587-592.

40. Prakash B, Shekar M, Maiti B, Karunasagar I, Padiyath S. Prevalence of Candida spp. Among healty denture and nondenture wearers with respect to hygiene and age. The Journal of Indian Prosthodontic Society. 2015; 15(1): 29-32.

41. Raju SB, Rajappa S. Isolation and identification of Candida from the oral cavity. International Scholarly Research Network ISRN Dentistry. 2011; ID 487921.

42. Rodrigues CF, Rodrigues ME, Henriques M. Candida sp. İnfections in patients with diabetes mellitus (Review). J Clin Med. 2019; 8 (76). 
43. Romeo O, Racco C, Criseo G. Amplification of hyphal wall protein 1 gene to distinguish Candida albicans from Candida dubliniensis. Journal of Clinical Microbiology. 2006; 44: 2590-2592.

44. Samaranayake L. Commensal oral Candida in Asian cohorts. Int J Oral Sci. 2009; 1:2-5.

45. Sampath A, Weerasekera M, Dilhari A, Gunasekara C, Bulugahapitiya U. Type 2 diabetes mellitus and .oral Candida colonization: Analysis of risk factors in a Sri Lankan cohort. Acta Odontologica Scandinavica. 2019; 77(7).

46. Sant'Ana Mariano PL, Milan EP, Matta DA, Colombo AL. Candida dubliniensis Identification in Brazilian Yeast Stock Collection. Mem Inst Oswaldo Cruz, Rio de Janeiro. 2003; 98(4): 533-538.

47. Salerno C, Pascale M, Contaldo M, Espozito V, Busciolano M, Milillo L, Guida A, Petruzzi M, Serpico R. Candidaassociated stomatitis (Review). Med Oral Patol Cir Bucal. 2011; 16(2): 139-143.

48. Senna AM, Vieirab MMF, Machado-de-Senac RM, Bertolind AO, Núñeze SC, Ribeirof MS. Photodynamic inactivation of Candida ssp. on denture stomatitis. A clinical trial involving palatal mucosa and prosthesis disinfection. Photodiagnosis and Photodynamic Therapy. 2018; 22: 212-16.

49. Sharma A. Oral candidiasis: An oppirtunistic infection: A review. International Journal of Applied Dental Sciences. 2019; 5(1): 23-27.
50. Singh A, Verma R, Murari A, Agrawal A. Oral candidiasis: An overview. J. Oral Maxillofac Pathol. 2014; 18:81-85.

51. Sullivan, DJ, Westerneng TJ, Haynes KA, Bennett DE, Coleman DC. Candida dubliniensis sp. nov.: phenotypic and molecular characterization of a novel species associated with oral candidosis in HIV-infected individuals. Microbiology. 1995; 141:1507-1521.

52. Thiyahuddin NM, Lamping E, Rich AM, Cannon RD. Yeast species in the oral cavity of older people: A comparison between people living in their own homes and those in rest homes. Journal of Fungi. 2019; 5(30).

53. Willis AM, Coulter WA, Sullivan DJ, Coleman DG, Hayes JR, Bell PM ve arkadaşları. Isolation of Candida dubliniensis from insulin-using diabetes mellitus patients. J Oral Pathol Med. 2000; 29: 86- 90.

54. Vila T, Sultan AS, Montelongo-Jauregui D, Jabra-Rizk MA. Oral candidiasis: A disease of opportunity. Journal of Fungi. 2020; 6(15).

55. Yücel A, Kantarcıŏlu AS. Candida albicans kökenlerinin kaç tanesi Candida dubliniensis? 1. Ulusal Mantar Hastalıkları ve Klinik Mikoloji Kongresi Kitabı.1996; 4-6 Mayıs, İzmir, Türkiye, s. 263-264.

56. Zomorodian K, Haghighi NN, Rajee N, Pakshir K, Tarazooie B, Vojdani M, Sedaghat F, Vosoghi M. Assessment of Candida species colonization and denture-related stomatitis in complete denture wearers. Medical Mycology. 2011; 49: 208-211. 